\title{
Use of a diazocoupling reaction for sensitive and selective spectrophotometeric determination of furosemide in spiked human urine and pharmaceuticals
}

\author{
Kalsang Tharpa, Kanakapura Basavaiah*, Kanakapura Basavaiah Vinay
}

\author{
Department of Chemistry, University of Mysore, Manasagangothri, Mysore-570006, India
}

Received 26 August 2009; Revised 17 November 2009; Accepted 17 December 2009

\begin{abstract}
Two simple, sensitive, and selective spectrophotometric methods for the determination of 5(aminosulfonyl)-4-chloro-2-((2-furanylmethyl)amino)benzoic acid (furosemide, FUR) are described. The methods are based on acid hydrolysis of FUR to free primary aromatic amine and diazotization followed by coupling with $N$-1-napthylethylene diamine (NEDA) (method A) or 4,5dihydroxynaphthalene-2,7-disulfonic acid (chromotropic acid, CTA) (method B). The colored reaction product can be measured spectrophotometrically at $520 \mathrm{~nm}(\operatorname{method} \mathrm{A})$ or $500 \mathrm{~nm}(\operatorname{method} \mathrm{B})$. Beer's law is obeyed over the ranges of $1.75-21.0 \mu \mathrm{g} \mathrm{mL}^{-1}$ and $2.5-30.0 \mu \mathrm{g} \mathrm{mL}^{-1}$, for method A and method B, respectively. Apparent molar absorptivities and Sandell's sensitivities (in L mol${ }^{-1} \mathrm{~cm}^{-1}$ and $\mu \mathrm{g} \mathrm{cm}^{-2}$ per 0.001 absorbance unit, respectively) were $1.34 \times 10^{4}$ and 0.0253 using NEDA as the coupling agent, and $8.5 \times 10^{3}$ and 0.0389 using CTA for the same purpose. Analysis of solutions containing seven different concentrations of FUR gave a correlation coefficient of 0.9979 using NEDA and 0.9984 using CTA, while the slope and the correlation coefficient of the regression equation were calculated. The reaction stoichiometry in both methods was evaluated by the limiting logarithmic method and was found to be $1: 1$ (diazotized FUR: NEDA or diazotized FUR: CTA). The methods were successfully applied to the determination of FUR in spiked human urine and in pharmaceutical formulations. The recovery of FUR from spiked urine was satisfactory resulting in the values of $(109.4 \pm 4.37) \%$ using NEDA and $(113.0 \pm 4.74) \%$ using CTA. Results of the analysis of pharmaceuticals demonstrated that the proposed procedures are at least as accurate and precise as the official method while a statistical analysis indicated that there was no significant difference between the results obtained by the proposed methods and those of the official method.
\end{abstract}

(c) 2010 Institute of Chemistry, Slovak Academy of Sciences

Keywords: diazotization, spiked human urine, pharmaceuticals, spectrophotometry

\section{Introduction}

Furosemide (FUR), chemically known as 5-(aminosulfonyl)-4-chloro-2-[(2-furanylmethyl)amino] benzoic acid (Fig. 1), is a potent diuretic. It is used to treat excessive fluid accumulation and swelling of the body caused by heart failure, cirrhosis, chronic kidney failure, and nephritic syndrome. The association of FUR and $N$-amidino-3,5-diamino-6-chloropyrazinecarboxamide hydrochloride (amiloride hydrochloride, AMU) furnishes a valuable natriuretic agent with a weaker kaliuretic effect, minimizing the risk of al- kalosis in the treatment of refractory edema associated with hepatic cirrhosis or congestive heart failure (Martindale: The extra pharmacopoeia, 1989). Owing to its extensive use as a powerful diuretic, FUR has long attracted the attention of many analysts. A variety of analytical methods for the determination of FUR in biological fluids and pharmaceutical samples have been proposed; the methods published in the nineties and up to 2007 have been reviewed by Espinosa Bosch et al. (2008). Official methods for the determination of FUR in dosage forms are based on titrimetry (European Di-

*Corresponding author, e-mail: basavaiahk@yahoo.co.in 
<smiles>NS(=O)(=O)c1cc(C(=O)OCCOC(=O)c2cc(N=Cc3ccco3)c(C(=O)O)cc2S(N)(=O)=O)c(N(C=O)Cc2ccco2)cc1Cl</smiles><smiles>NS(=O)(=O)c1cc(C(=O)O)c(NC(=O)c2ccco2)cc1Cl</smiles>

Nitrosation product,

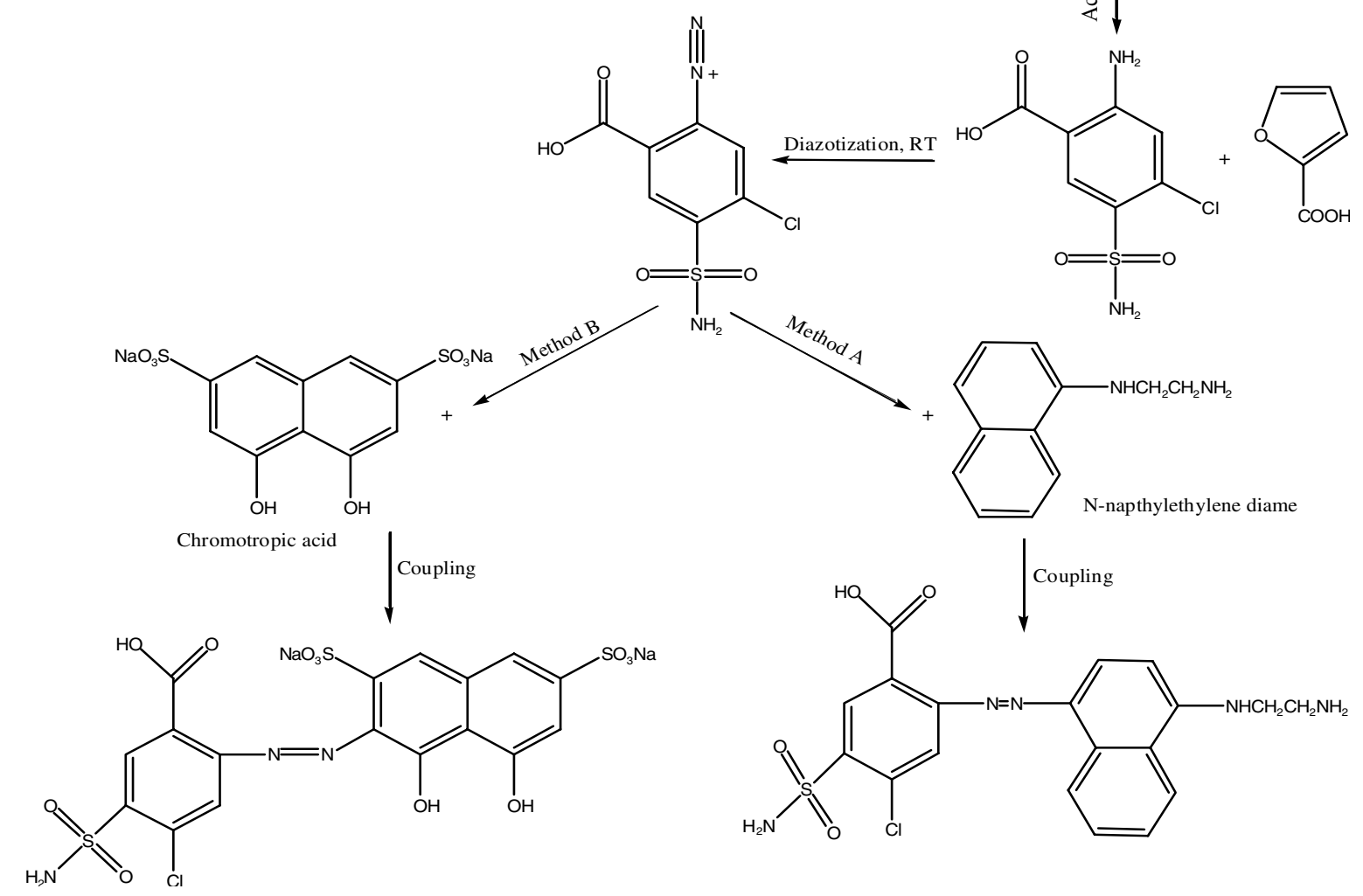

Fig. 1. Probable reaction pathway.

rectorate for the Quality of Medicines, 2001), spectrophotometry (The United States Pharmacopoeia, 2000), and HPLC (The British Pharmacopoeia Commission, 2002). Many techniques for the determination of FUR in pharmaceuticals or in biological matrix are available, they include UV spectrophotometry (Tescarollo Dias et al., 2005), spectrofluorimetry (Llorent-Martínez et al., 2005; Ioannou et al., 1998; Semaan et al., 2008), high performance liquid chromatography (HPLC) with UV detection (Jankowski et al., 1997), HPLC with fluorescence detection (Gomez et al., 2005; Reeuwijk et al., 1992; Abou-Auda et al., 1998), HPLC with amperometric detection (Guzmán et al., 2003), HPLC-DAD (Semaan et al., 2005a), LC-MS (Abdel-Hamid, 2000), GC-MS (Ptáček et al., 1996), micellar-LC (Carda-Broch et al., 2002), ratiospectra derivative spectroscopy (Millership et al.,
2005), and diffuse reflectance spectroscopy (Gotardo et al., 2004).

Some of these methods suffer from interference from the tablet matrix, whereas others are timeconsuming or require expensive equipment and are consequently not suitable for routine analysis, particularly in developing and under developed countries. From the above, the need for a fast, low-cost and selective method seems clearly apparent. Visible spectrophotometry continues to fulfill the above defined requirements. Quite a few visible spectrophotmetric methods (Živanović et al., 1990; Gölcü, 2006; Semaan et al., 2005b; Semaan \& Cavalheiro, 2006; Basavaiah et al., 2005; Sevillano-Cabeza et al., 1997; García et al., 1997; Mishra et al., 1990; Shah et al., 2005; Sastry et al., 1988, 1989; Issopoulos, 1989) have been developed for the quantification of FUR in pharmaceuti- 